\title{
Numerical Analysis of the Preloading Consolidation of the Soft Foundation with a Plastic Drainage Plate
}

\author{
Linjie Li $\mathbb{D}^{1},{ }^{1}$ Shuaidong Yang ${ }^{D},{ }^{2}$ and Tong $S u^{1}$ \\ ${ }^{1}$ Key Laboratory of Ministry of Education for Geomechanics and Embankment Engineering, Hohai University, \\ Nanjing 210098, China \\ ${ }^{2}$ Pearl River Water Resources Research Institute, 80 Tianshou Rd., Guangzhou, China \\ Correspondence should be addressed to Shuaidong Yang; 190202050002@hhu.edu.cn
}

Received 9 April 2021; Revised 17 June 2021; Accepted 27 July 2021; Published 4 August 2021

Academic Editor: Yi Zhang

Copyright (C 2021 Linjie Li et al. This is an open access article distributed under the Creative Commons Attribution License, which permits unrestricted use, distribution, and reproduction in any medium, provided the original work is properly cited.

\begin{abstract}
The permeability coefficient and void ratio are related to the stress state of the soil, which manifests as the temporal and spatial variability of consolidation. Based on the modified Cambridge model, this paper quotes the functional relationship between the soil permeability coefficient and void ratio and soil stress obtained by Tylor's research and then uses finite-element software ABAQUS and its secondary development platform to establish a plastic drainage plate surcharge preloading numerical model that considers the influence of the void ratio and permeability coefficient with stress changes. The results show that considering the variability of the permeability coefficient in the consolidation process of the soft foundation has a great influence on the change of the consolidation state but has a small effect on the final consolidation state. For soft foundation surcharge preloading reinforcement treatment, if the strength of the soft foundation is low but the surcharge is large, the geometric nonlinearity and material nonlinearity should be considered. Using the theory of large deformation consolidation to calculate the consolidation of soil is closer to the actual situation.
\end{abstract}

\section{Introduction}

Soft clay deposited by marine, lacustrine, and river facies is widely distributed along the coast and inland in China. This kind of soil is characterized by high compressibility, low strength, high water content, and poor water permeability. Under the effect of load, considerable settlement and settlement differences occur, which affects the construction quality and safety of the project and the normal use of the building.

With the development of economic construction in recent years, a large number of construction projects need to be built in soft soil and supersoft soil areas, and newer and higher requirements have been put forward for soft soil foundation treatment technology. At present, the main reinforcement treatment methods for soft soil foundations generally include the replacement method, the drainage consolidation method, the lime pile method, the highpressure jet grouting method, the deep mixing method, the sandstone pile method, reinforcement method, and so on [1-7]. Drainage plate preloading is a very common application in the drainage consolidation method. As an important member of foundation reinforcement technology, it is mainly used to treat silt or silt soil, flush fill, and saturated cohesive soil. The drainage plate preloading method is an effective soft foundation reinforcement method developed on the basis of the traditional sand well drainage preloading method. It is mainly used to treat foundations such as silt or silty soil, flush fill soil, and saturated clay soil. The basic principle of this method is to increase the drainage performance of the soil, improve the drainage conditions, and accelerate the drainage process of the soil by preloading, so as to promote the compression and consolidation of the soft foundation and improve its bearing capacity and stability.

As the basic theory of analysis and calculation in soft foundation reinforcement engineering, consolidation theory is the basis for soft foundation consolidation calculation. Terzaghi was the first to establish the basic differential 
equation of one-dimensional consolidation based on the principle of effective stress and the continuum equation of seepage flow. Because of its simple form and obtainable analytical solutions under certain initial and boundary conditions, it has been widely used in engineering. However, Terzaghi's consolidation theory is based on the assumption of constant compressibility and the permeability coefficient, which is obviously inconsistent with the actual situation that the permeability coefficient changes nonlinearly along the depth of the soil and changes with the change of the consolidation stress state. In addition, an important assumption in this theory is that the deformation of the soil is based on the theory of small deformation, which often results in large deviations in the calculation of the consolidation of soft clay foundations or foundations under heavy loads. In order to reflect the actual situation, Gibson et al. [8] assumed that the large-strain consolidation coefficient in the governing equation is linearly related to the void ratio, and the gravity coefficient is a constant. The finite-difference method was used to study the consolidation of thin soil layers. Poskitt [9] elaborated on the Gibson theory and considered the linear changes of soil compressibility and permeability during the consolidation process, using the perturbation method to obtain an analytical solution to the one-dimensional largestrain consolidation equation. Gibson et al. [10] assumed that both the large strain area coefficient and the gravitational coefficient are constant during the consolidation process, solved the equation and compared the calculation result with the solution. The research results show that the calculation result of the consolidation degree of the largestrain consolidation theory is safe. Davis and Raymond [11] obtained an analytical solution under constant load based on the assumption that the permeability coefficient changes linearly with depth, and the initial effective stress is constant. On the basis of Gibson's one-dimensional large-strain theory and Barron's free strain theory, Geng and Yu [12] present a governing equation which considers the radial and vertical flows, the weight of the soil, time-dependent surcharge, and vacuum preloading, along with variable hydraulic conductivity and compressibility during consolidation. Based on the analytical solution of one-dimensional linear elastic consolidation of layered foundations, Hui [13] used a semianalytical method to comprehensively analyze the properties of soil nonlinearity, rheology, soil weight, and variable load. Hong et al. [14] used a combination of explicit and implicit differences to solve the equation on the basis of the theory and studied the influence of factors such as initial conditions and boundary conditions on the calculation results. Geng et al. [15] presented an analytical solution that reflected the difference between the vacuum preloading systems under time-dependent surcharge preloading, and the results were in accordance with the laboratory and field results. Xie et al. [16] established a one-dimensional large-strain consolidation control equation that can consider the influence of load changes, soil weight, and other factors under Lagrange coordinates, using excess pore pressure as the control variable. Xie Xinyu [17] derived the one-dimensional large-strain surface bonding equation based on the mixture theory and believes that the consolidation theory based on the mixture theory is by far the most common consolidation theory. Applying the group transformation method, the explicit or implicit solution of the one-dimensional large-strain consolidation equation under certain specific conditions is obtained. In order to investigate the reinforcement effect of the SLR under vacuum-surcharge preloading, Wang et al. [18] conducted a series of laboratory tests for combination of vacuum pressure and surcharge load with different loading rates. Liu et al. [19] proposed an analytical solution that considered the effect of vacuum pressure loss, radial and vertical flow, smear effect, void ratio-dependent compressibility and permeability, and time-dependent surcharge preloading.

Relying on actual engineering, this article uses finiteelement software ABAQUS to perform a numerical simulation study on the soft foundation treatment of a plastic drainage plate with surcharge pressure considering the variability of the permeability coefficient and large deformation consolidation. The numerical calculation results are compared with the classical Terzaghi calculation results and the actual measured data to obtain the influence law of considering the variability of seepage and large deformation on the numerical calculation of soft soil consolidation and predict its development trend. In addition, the results are used to analyze the consolidation settlement of the soft foundation reinforced by the preloading of the drainage plate by the numerical simulation method's practicality and effectiveness in forecasting.

\section{Engineering Information}

2.1. Project Conditions. This project is the construction of a water system and landscape engineering on the west side of Fenghuang Avenue on Lingshan Island in Guangdong Province. There are 5 rivers planned in this area, with a total length of $3868.1 \mathrm{~m}$. Among them, the two existing rivers in the planned Zong Er Chong and Heng Er Chong are going to be rebuilt, with a length of $1584.2 \mathrm{~m}$. The main task of the project is to reconstruct the internal water system on the west side of Lingshan Island to form a river network and ensure the connection of the water system. The main construction tasks are to complete the planned soil excavation, foundation treatment, ecological slope protection construction, and so on. In this simulation analysis, the planned longitudinal second swell was selected as the numerical simulation object for the preloaded soft foundation treatment, and the cross section BM650C with complete and reliable monitoring data was selected as the numerical modeling sample section on the swell.

2.2. Soil Properties. The Zong Er Chong was rebuilt on the basis of the original Dong Wei Chong. According to the site geological survey report, the distribution of the foundation soil layer can be obtained as (1) silty clay layer, (2) silty sand layer, (3) sand layer, (4) silty clay layer, (5) sandy clay layer, and (6) bedrock layer. The simplified soil section is shown in Figure 1. The physicomechanical parameters of soils are summarized in Table 1. 


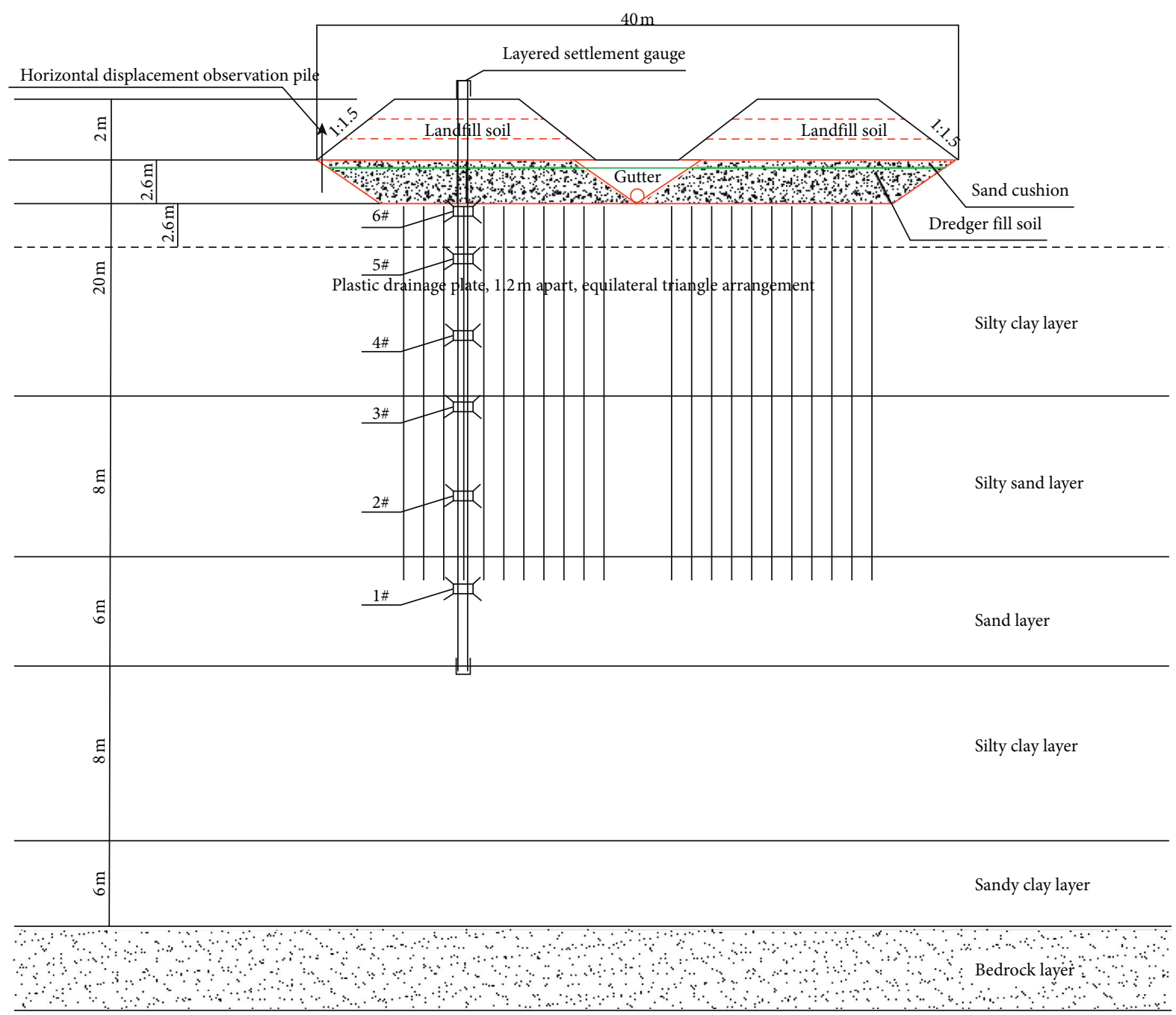

FIGURE 1: Simplified soil layer distribution (not to scale).

TABLe 1: Physicomechanical parameters of soils.

\begin{tabular}{|c|c|c|c|c|c|c|c|c|c|c|}
\hline $\begin{array}{l}\text { Layer } \\
\text { name }\end{array}$ & $\begin{array}{c}\text { Soil } \\
\text { thickness } \\
\text { (m) }\end{array}$ & $\begin{array}{c}\text { Water } \\
\text { content } \\
\omega(\%)\end{array}$ & $\begin{array}{c}\text { Weight } \\
\gamma \\
\left(\mathrm{kN} / \mathrm{m}^{3}\right)\end{array}$ & $\begin{array}{c}\text { Void } \\
\text { ration } \\
e_{0}\end{array}$ & $\begin{array}{l}\text { Compression } \\
\text { modulus } E_{s}\end{array}$ & $\begin{array}{l}\text { Permeability } \\
\text { coefficient } k_{v} \\
\quad(\mathrm{~m} / \text { day })\end{array}$ & $\begin{array}{l}\text { Friction } \\
\text { angle } \varphi \\
\left(^{\circ}\right)\end{array}$ & $\begin{array}{c}\text { Cohesion } \\
c(\mathrm{kPa})\end{array}$ & $\begin{array}{c}\text { Consolidation } \\
\text { coefficient } C_{v} \\
\left(10^{-3} \mathrm{~cm}^{2} / \mathrm{s}\right)\end{array}$ & $\begin{array}{c}\text { Consolidation } \\
\text { coefficient } C_{H} \\
\left(10^{3} \mathrm{~cm}^{2} / \mathrm{s}\right)\end{array}$ \\
\hline $\begin{array}{l}\text { Silty } \\
\text { clay } \\
\text { layer }\end{array}$ & 20 & 53.5 & 17.0 & 1.449 & 2.10 & $0.95 \times 10^{-5}$ & 6.5 & 6.6 & 2.514 & 10.780 \\
\hline $\begin{array}{l}\text { Silty } \\
\text { sand } \\
\text { layer }\end{array}$ & 8 & 45.7 & 18.7 & 1.367 & 4.70 & $7.43 \times 10^{4}$ & 16.1 & 8.5 & 2.780 & 13.830 \\
\hline $\begin{array}{l}\text { Sand } \\
\text { layer }\end{array}$ & 6 & 33.0 & 17.5 & 0.710 & 8.60 & $5.01 \times 10^{-2}$ & 28.0 & 0.0 & $10-3$ & $10-3$ \\
\hline $\begin{array}{l}\text { Silty } \\
\text { clay } \\
\text { layer }\end{array}$ & 8 & 46.5 & 17.5 & 1.237 & 2.80 & $4.49 \times 10^{-5}$ & 8.0 & 11.0 & 1.194 & 6.080 \\
\hline $\begin{array}{l}\text { Sandy } \\
\text { clay } \\
\text { layer }\end{array}$ & 5 & - & 19.5 & 1.012 & 6.00 & $6.05 \times 10^{-3}$ & 26.0 & 12.0 & - & - \\
\hline
\end{tabular}

2.3. Foundation Reinforcement Plan. The width of the Zong Er Chong is $43 \mathrm{~m}$, and the soft foundation is reinforced. After cleaning the basement, the elevation of the bottom of the creek is $2.5 \mathrm{~m}$. After the bottom of the creek is filled with sand to an elevation of $4.5 \mathrm{~m}$, a $50 \mathrm{~cm}$ medium-coarse sand cushion is laid; the permeability coefficient is greater than 
$0.01 \mathrm{~cm} / \mathrm{s}$, and the drainage plate is preloaded. After the drainage plate is completed, a layer of $300 \mathrm{~g} / \mathrm{m}^{2}$ nonwoven geotextile is laid and then stacked and preloaded in layers. The stacking preloading backfilling shall be filled in layers, each with a thickness of $50 \mathrm{~cm}$. The stacking load should be loaded evenly in layers to avoid excessive local stacking loads, and the loading time of the lower layer should be determined according to the settlement data. During the filling process, the settlement and stability of each layer are monitored. An ordinary B-type plastic drainage plate is used as the vertical drainage channel, arranged in a regular triangle, with a distance of $1.2 \mathrm{~m}$. The plastic drainage plate has a cross-sectional width of $100 \pm 2 \mathrm{~mm}$, a thickness of $4.0 \mathrm{~mm}$, longitudinal water flow, and a membrane permeability coefficient of $\geq 5 \times 10^{-4} \mathrm{~m} / \mathrm{s}$. The plastic drainage plate is required to pass through the silty soft soil layer and the weak underlying layer into the sand layer about $1.0 \mathrm{~m}$.

\section{Finite-Element Model}

3.1. Secondary Development of the Constitutive Model. In this paper, the modified Cambridge constitutive model is used for the soft foundation. The modified Cambridge model in ABAQUS defaults so that the void ratio of the soil and the permeability coefficient remain unchanged. In order to make up for the deficiencies of the built-in model, user subroutines are written to realize the change of the void ratio and permeability coefficient with the consolidation stress. A large number of experiments and practices have proved that a semilogarithmic linear correlation between the permeability coefficient and void ratio empirical formula proposed by Taylor [20] in 1948 can well describe the relationship between the permeability coefficient and void ratio of soft soil. The formula is as follows:

$$
\lg k=\lg k_{0}+\frac{e-e_{0}}{C_{k}}
$$

where $e_{0}$ is the initial void ratio, $k_{0}$ is the initial permeability coefficient, and $C_{k}$ is the slope of the $e$-logk curve, under normal circumstances, $C_{k}=0.5 e_{0}$. According to the formula, combined with the initial conditions, the relationship between $k$ and $e$ can be obtained, as shown in Figure 2.

\subsection{Choice of Material Constitutive}

(1) Constitutive model of plastic drainage plate: the plastic drainage plate is a typical composite material, and it is difficult to determine its constitutive relationship. For the sake of simplification, the plastic drainage plate is simplified into a continuous medium in engineering, and the linear elastic model is used to analyze it.

(2) Constitutive model of the dredger fill, sand cushion, and landfill: both the D-P model and the M-C model are suitable for granular materials. In order to keep the yield surface convex on the plane in the D-P model, a friction angle of less than $22^{\circ}$ is required. The friction angle of materials such as the dredger fill

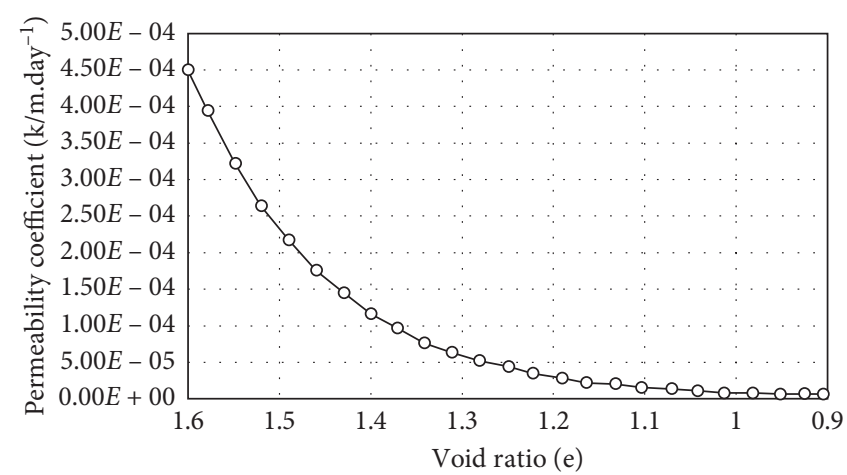

FIgURE 2: Relationship between permeability coefficient and void ratio of soft soil.

and landfill is often greater than $22^{\circ}$, so the $\mathrm{M}-\mathrm{C}$ model is used.

(3) Foundation structure constitutive model: a lot of engineering practices and theories prove that the MCC model is suitable for normal consolidated clay and underconsolidated clay. Therefore, the MCC constitutive model with nonlinear and hardening characteristics in this numerical simulation is selected.

3.3. Material Parameters. According to the survey report and indoor geotechnical test and convert, the parameters of the drainage plate and the soils are shown in Tables 2 and 3.

3.4. Loading Steps. According to the actual construction plan of the project, the loading process is divided into three main stages: sand filling (including sand cushion), layered filling, and preloading. There is a certain time interval between each stage and each loading process, and it can be regarded as an isokinetic process. The loading process can be simplified as follows: 1 to 3 days are to fill the first layer of sand with a thickness of $1 \mathrm{~m}$. After an interval of 2 days, the second layer of sand shall be blow-filled in 6 to 8 days with a thickness of $1 \mathrm{~m}$. After an interval of 2 days, a $0.5 \mathrm{~m}$ thick sand cushion is laid out in 11 to 12 days. After an interval of 109 days, the landfill will start. The total thickness of the landfill is $2 \mathrm{~m}$, and the landfill is divided 4 times. The first landfill thickness is about $72 \mathrm{~cm}$, the total time is 3 days, and the preloading is 100 days. The thickness of the second filling is about $17 \mathrm{~cm}$, which takes 2 days, and the precompression is 12 days. The thickness of the third filling is about $23 \mathrm{~cm}$, which takes 2 days, and the preloading is 5 days. The thickness of the fourth filling is about $88 \mathrm{~cm}$, which takes 3 days, and the preloading is 243 days. The loading curve is shown in Figure 3.

3.5. Establishment of the Numerical Model. According to the soil condition of the selected section and the construction plan, considering the symmetry of the stacking construction, half of the section model is established. The calculation model can be summarized as follows. The width of the 
TABle 2: Parameters of the material.

\begin{tabular}{lccccccc}
\hline Material & Constitutive model & $E(\mathrm{MPa})$ & $C(\mathrm{kPa})$ & $\Phi\left(^{\circ}\right)$ & $\Psi\left(^{\circ}\right)$ & $\mu$ & $\left.k_{0}(\mathrm{~m} \mathrm{day})^{-1}\right)$ \\
\hline Blow sand & M-C & 30 & 2.42 & 31.21 & 0 & 0.26 & 1.05 \\
Sand cushion & M-C & 45 & 1.23 & 38.03 & 0 & 0.25 & 2.35 \\
Landfill & M-C & 20 & 12.74 & 26.12 & 0 & 0.31 & - \\
Drainage plate & Hooke & 20 & - & - & - & 0.3 & 4.33 \\
\hline
\end{tabular}

TABLE 3: Calculation parameters of the soft soil foundation.

\begin{tabular}{lccccccccccc}
\hline Material & Constitutive model & $\gamma_{\text {sat }}\left(\mathrm{kN} / \mathrm{m}^{3}\right)$ & $\kappa$ & $\mu$ & $\lambda$ & $M$ & $a_{0}$ & $\beta$ & $K$ & $e_{0}$ & $k_{0} \mathrm{~m} / \mathrm{day}$ \\
\hline Soil 1 & MCC & 17.0 & 0.102 & 0.30 & 0.57 & 1.00 & 0 & 1 & 1 & 1.449 & $0.95 \times 10^{-5}$ \\
Soil 2 & MCC & 18.7 & 0.065 & 0.30 & 0.54 & 1.42 & 0 & 1 & 1 & 1.367 & $7.43 \times 10^{-3}$ \\
Soil 3 & MCC & 17.5 & 0.025 & 0.25 & 0.53 & 1.34 & 0 & 1 & 1 & 0.710 & $5.01 \times 10^{-1}$ \\
Soil 4 & MCC & 17.5 & 0.042 & 0.33 & 0.52 & 1.34 & 0 & 1 & 1 & 1.237 & $4.49 \times 10^{-5}$ \\
Soil 5 & MCC & 19.5 & 0.063 & 0.20 & 0.52 & 1.22 & 0 & 1 & 1 & 1.012 & $6.05 \times 10^{-2}$ \\
\hline
\end{tabular}

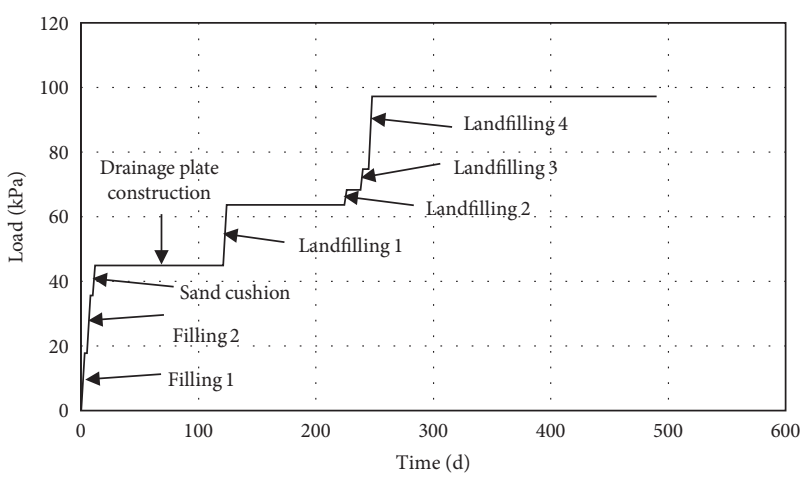

FIgURE 3: Loading process curve.

foundation model stacking area is $40 \mathrm{~m}$, the horizontal influence area is $80 \mathrm{~m}$, the calculating depth is taken to $47 \mathrm{~m}$ below the ground surface and the groundwater level is taken to the ground surface. From top to bottom, they are landfill, sand cushion, sand-filled layer, and different soil layers down. According to the grid division, the calculation model has a total of 6236 calculation nodes and 6077 calculation units. The soil element, drainage plate element, dredger fill element, and sand cushion element adopt the four-node plane pore flow element CPE4P, which is calculated by coupling of seepage and consolidation. The landfill element adopts the four-node plane strain element CPE4 without calculating its pore pressure. The simplified model is shown in Figure 4.

\section{Results and Analysis}

According to the construction situation, the soil stress and strain, the change of excess pore pressure, and the displacement change during the preloading process are numerically simulated. The numerical calculation results and the monitoring values are compared and analyzed.

4.1. Analysis of Surface Settlement Results. The project monitors the surface settlement of the left and right landfills at three locations. They are BM650A-ZEC, BM650B-ZEC, and BM650C-ZEC (left pile, middle pile, and right pile), which are referred to as measuring points $A, B$, and $C$, respectively. Take Point $B$ as an example. From the monitoring values in Figure 5, it can be seen that the settlement changes stepwise with the loading process, and the final settlement result is between 2.23 and $2.27 \mathrm{~m}$.

From Figure 6, it can be clearly seen that the settlement value obtained based on the constant $k$ is obviously greater than the monitoring value, reaching $2.62 \mathrm{~m}$. The settlement change rate is relatively larger in each construction step. The settlement value calculated based on the nonlinear change of $k$ with the void ratio is consistent with the monitoring values. Although there is a significant difference in the early stage of loading (within 70 days), the difference in the middle and late stages gradually decreases and tends to be stable. The main reason for this difference is that the construction and drainage conditions in the early stage of construction and the initial stage of the installation of the drainage plate are better than those of numerical simulation, which means the settlement speed obtained from the monitoring value is faster. However, when the plastic drainage plate works, the drainage conditions of the two are similar; the settlement value will gradually approach. The settlement curve calculated based on the large-strain theory is between the constant $k$ and the change $k$ curve, which means that the numerical simulation of the fluid-structure interaction based on largestrain theory is better than conventional consolidation theory.

From Figure 7, it can be seen that in the initial stage of construction, the relative error rate between the numerical calculation and the monitoring value is very large. As the construction progresses, the relative error rate under the condition of $k$ changes gradually decreases and tends to be stable and remains at about $1 \%$. Based on the constant $k$, the error rate also tends to decrease in the later period, but it remains at a high value and reaches about $18 \%$.

4.2. Analysis of Layered Settlement Results. Figure 8 shows the time-history change curve of the layered settlement value measured by the $1 \#-6 \#$ magnetic ring of the layered settlement pipe on the left. From the monitoring results, the settlement law of the soft foundation at each depth corresponds to the construction loading process. In addition, the 


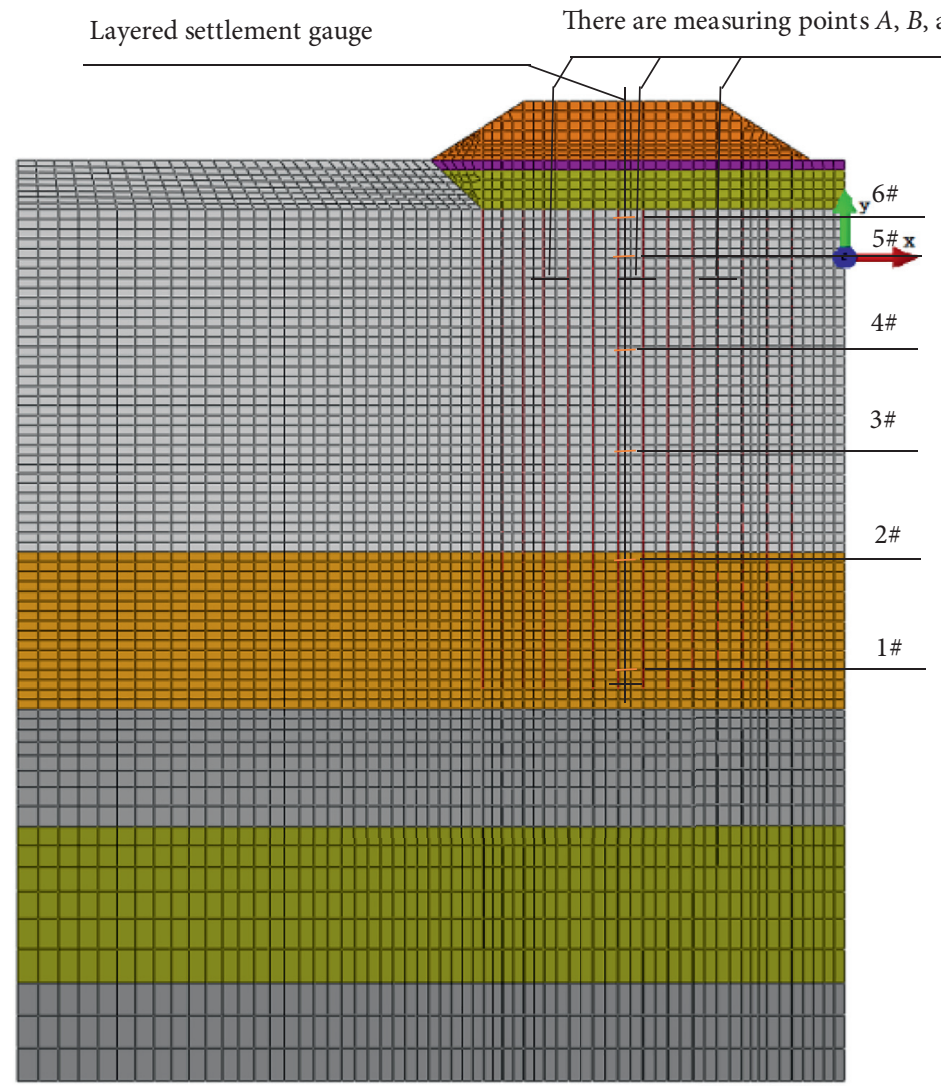

FIGURE 4: Simplified preloading model.

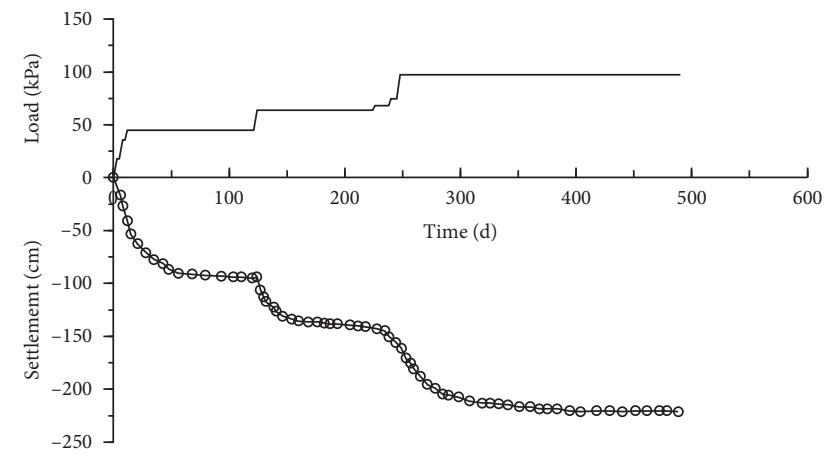

FIGURE 5: Settlement measured results.

settlement deformation value measured from the $1 \#$ to $6 \#$ magnetic rings decreases successively, and the deformation amplitude also decreases. Due to stress diffusion, the additional stress generated by the upper load decreases as the depth increases. Figure 9 shows the layered settlement monitoring values and numerical calculation results of the 1\#-3\# magnetic ring with obvious settlement changes. The gap between the monitoring results and numerical values is large in the early stage of construction. As the construction progresses, the trend of change gradually approaches. This result is similar to the aforementioned surface settlement change law; the numerical result based on the nonlinear change of the permeability coefficient $k$ with the void ratio is very close to the settlement result obtained by monitoring,

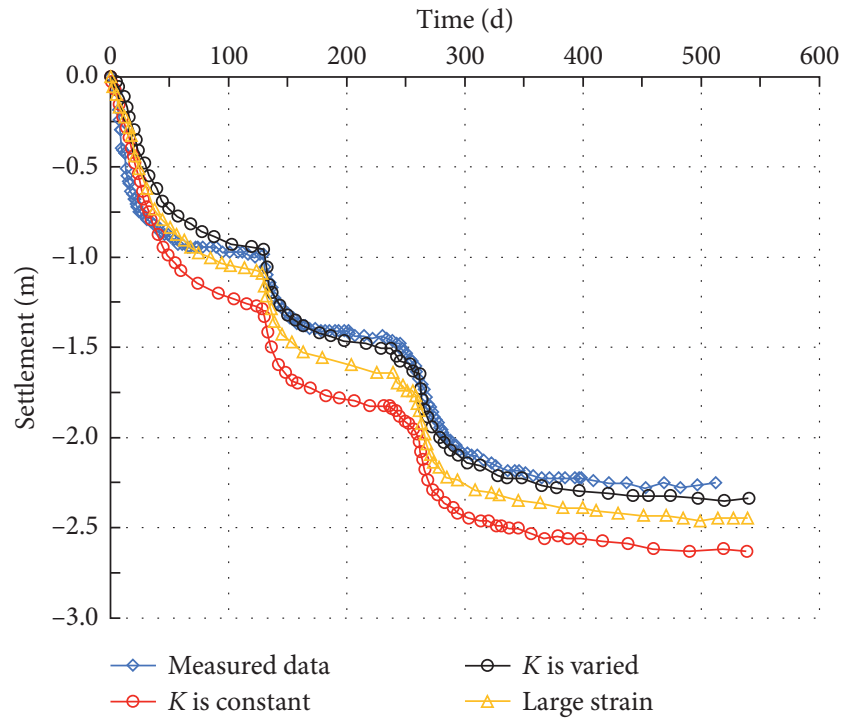

FIgURE 6: Comparison of the settlement monitoring values and the numerical calculation results (Point $(B)$ ).

which is obviously better than the result of constant permeability coefficient.

4.3. Analysis of Horizontal Displacement Results. It can be seen from Figure 10 that there is a significant difference between the numerical calculation values and monitoring 


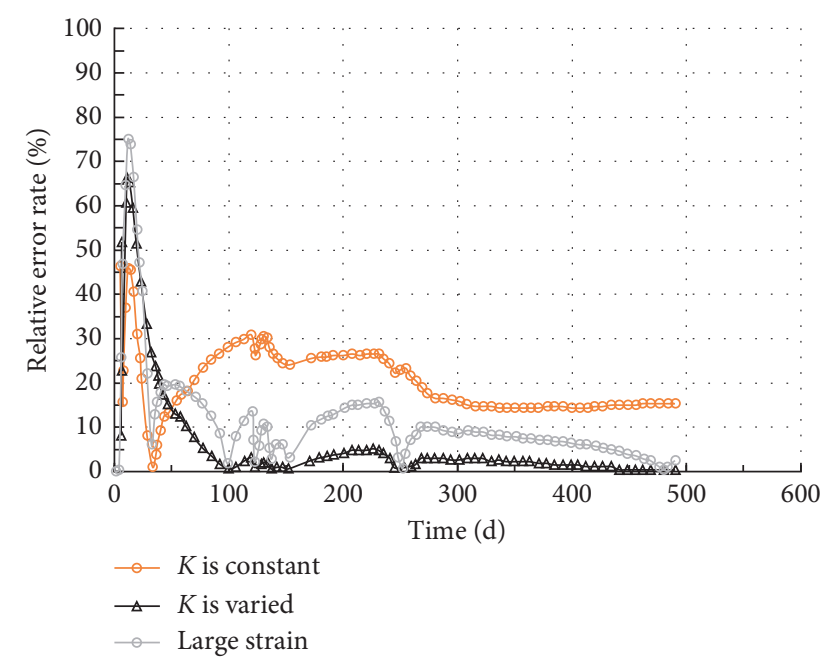

FIGURE 7: Relative error rate between the numerical calculation results and the settlement monitoring value.

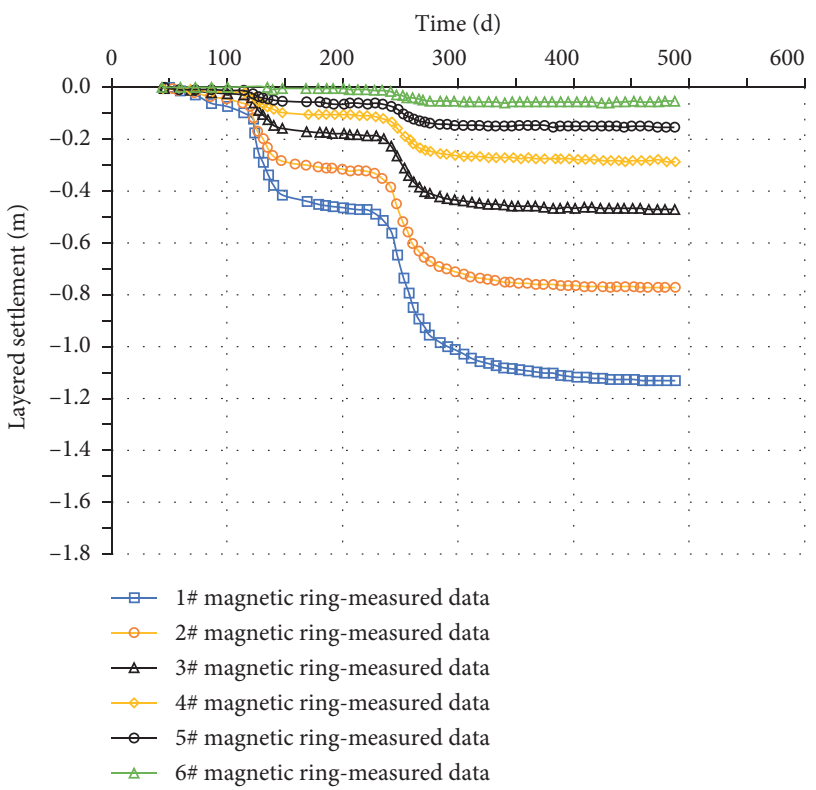

FIgURE 8: Time-history change curve of the layered settlement monitoring value.

values near the stacking area. The numerical calculation result changes significantly during the loading stage, while the monitoring result changes relatively smoothly. This difference is caused by complex field conditions, and numerical calculations are difficult to accurately simulate the actual situation. In addition, the displacement increases rapidly during loading, while the displacement decreases slowly during static preloading. Moreover, without considering the variability of the permeability coefficient, the horizontal displacement decreases more significantly. The soil is compressed during the consolidation process of the soft foundation. Under the effect of the drainage plate, this compression deformation is faster, so the pores of the soil become smaller and smaller, and the permeability worsens. Low permeability will hinder the drainage and consolidation

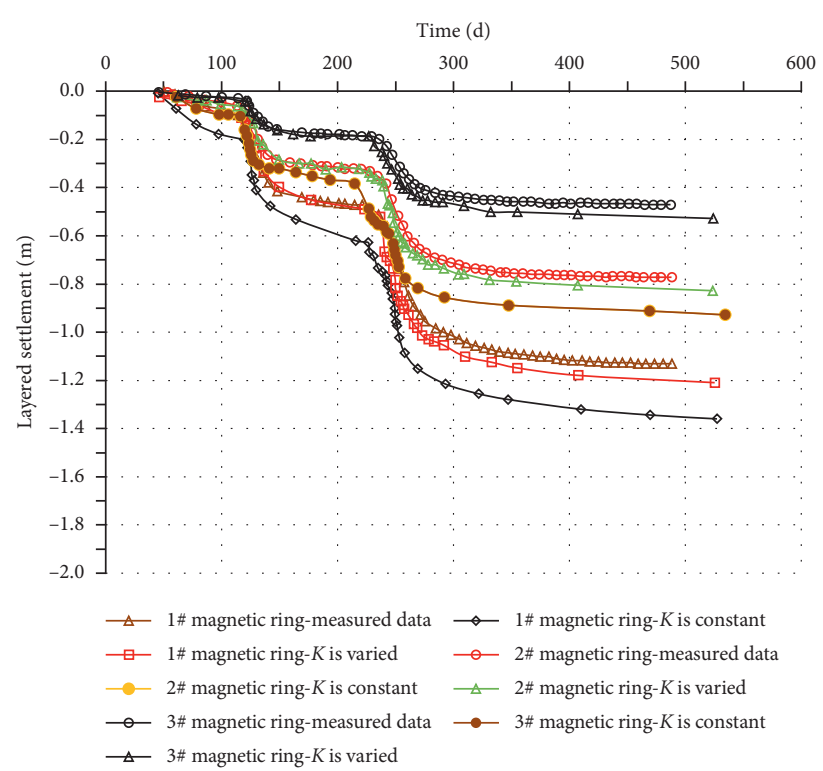

FIGURE 9: Comparison of the monitoring values and the numerical calculation results of the layered settlement.

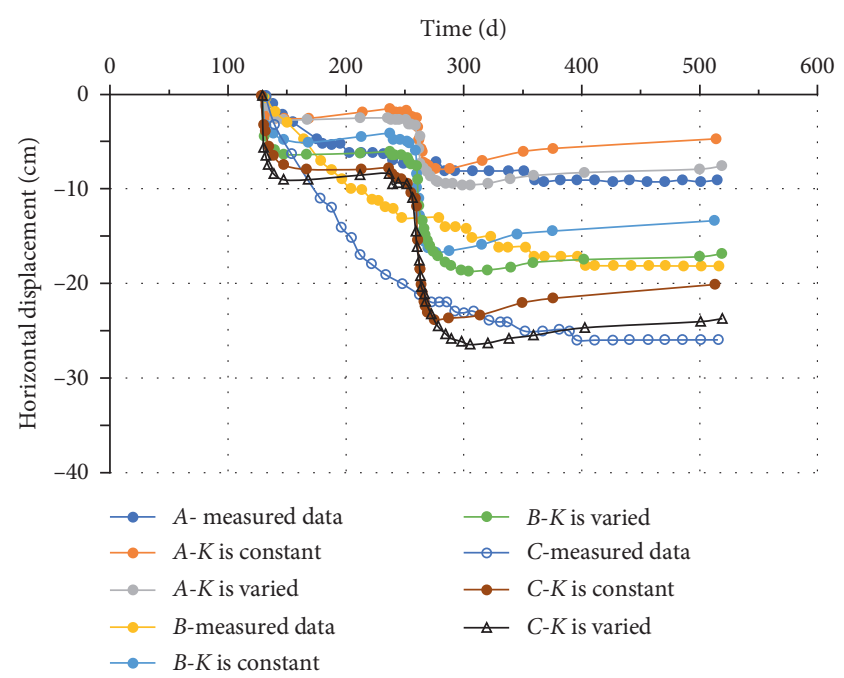

FIgURE 10: Comparison of the monitoring values and the numerical calculations of the ground horizontal displacement.

of soil, which will slow down the deformation. Without considering the variability of the permeability coefficient, such obstacles will not occur. The soil will continue to compress and deform, resulting in an increase in the vertical compression and a decrease in the horizontal displacement. This also explains that at the same time node, the horizontal displacement calculated without considering the permeability variability is smaller and more obvious than considering the permeability coefficient variability.

Figure 11 shows the horizontal displacement curves of the soft foundation at different depths during each construction process, which are calculated based on different theoretical calculations. Figure 11(a) shows the curve of the horizontal displacement of the soft foundation in various construction stages with depth when considering the 

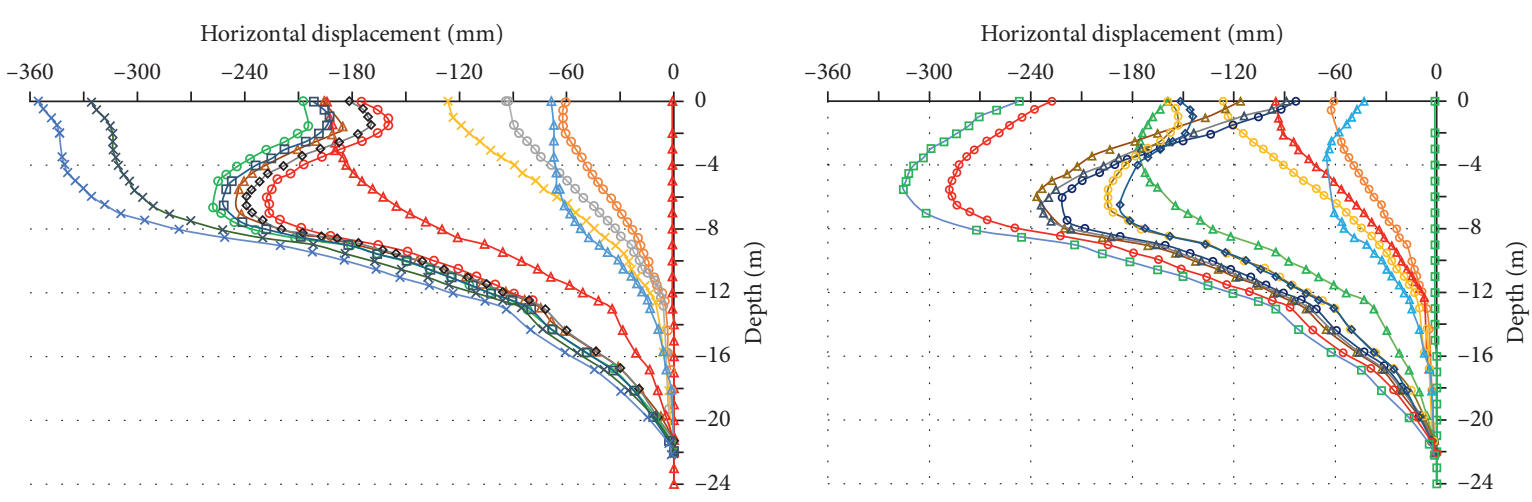

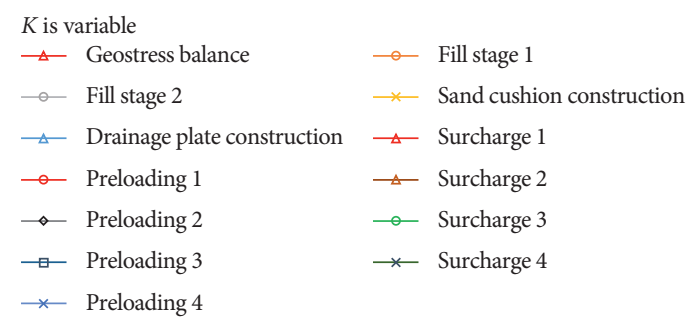

(a)

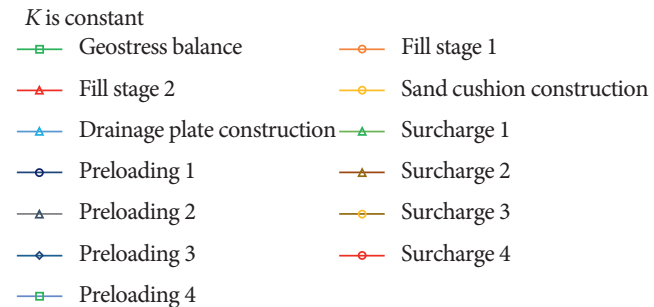

(b)

FIGURE 11: Horizontal displacement changes in depth.

nonlinear variability of the permeability coefficient. Figure 11(b) shows the variation curve of the soft foundation in each construction stage when the permeability coefficient is constant. From Figures 11(a) and 11(b), the horizontal displacement from top to bottom generally shows a trend of large and small, which is more obvious before the construction stage of the plastic drainage plate. After entering the preloading stage, the horizontal displacement increases and then decreases in depth. This phenomenon is caused by the formation of stress bubbles in the soft foundation when the soft soil is subjected to a large upper load, and the soft soil is caused by the coordination of deformation. During the preloading stage of the soft foundation, its horizontal displacement will gradually decrease. During the loading stage, the surrounding soil is squeezed to cause horizontal displacement. The excess pore water pressure in the soft foundation is then quickly dissipated under the action of the plastic drainage plate, and the soft foundation undergoes a large vertical settlement. The surrounding soft soil tends to move closer to the center, which causes the horizontal displacement of the surrounding soft foundation to be reversed. Therefore, compared to the previous loading process, the surrounding horizontal displacement is smaller.

4.4. Analysis of Excess Pore Water Pressure Results. The distribution and dissipation of excess pore water pressure is an important indicator, reflecting the development of the consolidation process of soft foundations. A total of six pore pressure gauges are buried in the selected section, and they are buried symmetrically at different depths in the middle of the left and right landfills. They are named $A, B, C$ and $D, E, F$, and the pore pressure gauges are buried at 6,11 , and $18 \mathrm{~m}$. Take the left as an example. The monitoring point is located within the depth of the plastic drainage plate. From Figure 12, the pore pressure changes significantly, showing the characteristics of rapid increase and dissipation. When considering the permeability variability of soft soil, the measured excess pore pressure at the same part of the soil is larger than the excess pore pressure without considering the permeability variability, and the dissipation rate of pore pressure is slower. This gap is especially obvious in shallow soils. It decreases as the depth increases and eventually becomes consistent. As the upper soil compresses and deforms significantly under the load, the permeability coefficient of the soil will be significantly reduced, resulting in a slower dissipation rate of excess pore pressure than that obtained without considering the change of the permeability coefficient. As the depth increases, the compression of the soil layer gradually decreases, and the gap between the two gradually decreases.

From Figure 13, in the shallow and medium soils directly affected by the drainage plate, the excess pore pressure changes significantly, which is characterized by a rapid rise in the loading stage and a rapid decline in the precompression stage, especially in the filling construction stage and the large heap load. The excess pore pressure value corresponding to the construction stage of Landfills 1 and 4 is much larger, which exceeds the upper loading value. It is especially obvious in the sand filling construction stage, where there is no plastic drainage plate. This is called the Mandel-Cray effect [21, 22]. 


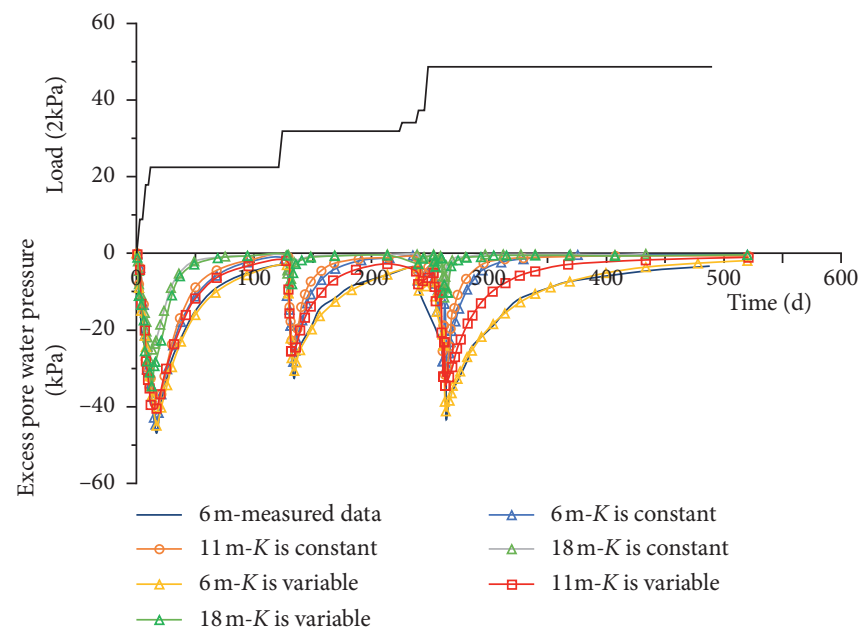

FIgURE 12: Comparison in soil excess pore water pressure at monitoring locations.

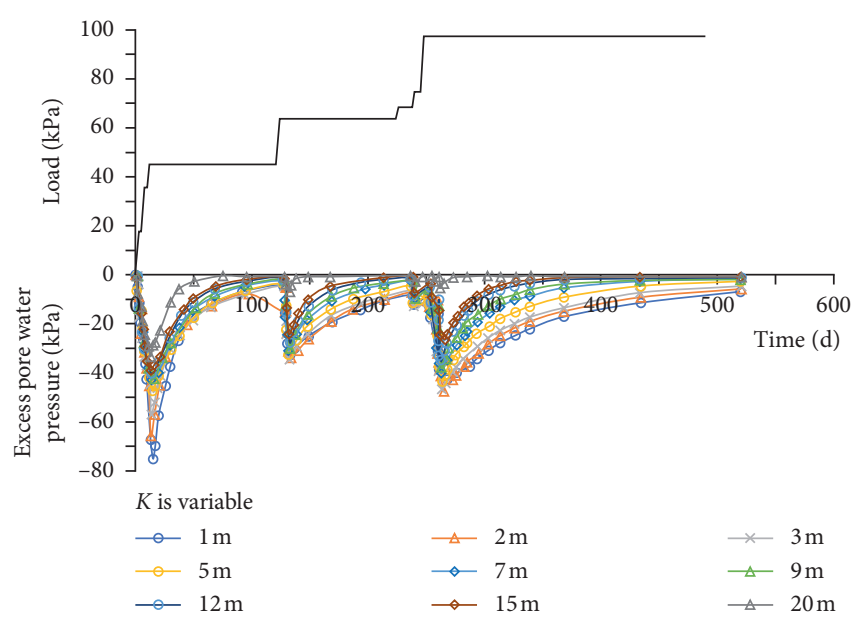

FIGURE 13: Variation curve of the excess pore water pressure of the soil layer under the drainage plate.

\section{Conclusion}

This article focuses on the nonlinear change of the permeability coefficient of soft soil along the depth. The consolidation theory of soft soil is developed by the ABAQUS secondary development platform. On this basis, combined with an engineering example of soft foundation reinforcement treatment in Lingshan Island rivers, finite-element calculations are carried out on the basis of field measuring data. Compared with the measuring data, the influence law of soft soil consolidation characteristics on the calculation of soft foundation reinforcement treatment is studied. The conclusions are as follows:

(1) The choice of a constitutive model of soft soil consolidation has a great influence on the calculation results of consolidation, and it is more appropriate to use the modified Cambridge model for normally consolidated soft clay.

(2) Considering the variability of the permeability coefficient during the consolidation process of soft foundations has a great influence on the change of the consolidation state, and the most direct factor is to affect the speed of consolidation. The consolidation speed, considering the permeability variability, is significantly lower than the consolidation speed without considering the permeability variability but has little effect on the final consolidation state.

(3) For the preloading and precompression reinforcement of soft foundations, if the strength of the soft foundation is low and the surcharge is large, the geometric nonlinearity and material nonlinearity should be considered, and the large deformation consolidation theory is used to calculate the consolidation problem of the soil.

(4) The calculated results by considering the permeability variability of soft foundations are more consistent with actual project monitoring values, which can better guide the selection of construction schemes and better predict and evaluate the development trend of soft foundation surcharge preloading reinforcement treatment.

\section{Data Availability}

The data used to support the findings of this study are available from the corresponding author upon request.

\section{Conflicts of Interest}

The authors declare that they have no conflicts of interest.

\section{References}

[1] X. Gong, Fundamental Treatment Manual, China Construction Industry Press, Beijing, China, 2008.

[2] Z. Qin, X. Yuan, B. Niu, and Z. Cao, "Vibroflotation method for foundation treatment of replaced sandy soil indeepwater marine environment," Chinese Journal of Geotechnical Engineering, vol. 42, no. 10, pp. 1940-1946, 2020.

[3] J. Jiang, G. Cao, and R. Liu, "Field test on behaviours of marine soft soil foundation treated with plastic," Rock and Soil Mechanics, vol. 36, no. S2, pp. 551-558, 2015. 
[4] T. N. Nguyen, D. T. Bergado, M. Kikumoto, P. H. Dang, S. Chaiyaput, and P.-C. Nguyen, "A simple solution for prefabricated vertical drain with surcharge preloading combined with vacuum consolidation," Geotextiles and Geomembranes, vol. 49, no. 1, pp. 304-322, 2021.

[5] H. L. Liu, Y. L. Cui, Y. Shen, and X. Ding, "A new method of combination of electroosmosis, vacuum and surcharge preloading for soft ground improvement," China Ocean Engineering, vol. 28, pp. 511-528, 2014.

[6] Y. Cui, J. Tu, X. Wang, H. Diao, and Q. Ge, "Design method and verification of electroosmosis-vacuum preloading method for sand-interlayered soft foundation," Advances in Civil Engineering, vol. 2020, no. 3, Article ID 1929842, 9 pages, 2020.

[7] C. Xiao and S. Chu, "The application of plastic drainage plate preloading method in soft foundation treatment," Construction Technology, vol. 41, no. 1, pp. 64-68, 2012.

[8] R. E. Gibson, G. L. England, and M. J. L. Hussey, "The theory of one-dimensional consolidation of saturated clays," Géotechnique, vol. 17, no. 3, pp. 261-273, 1967.

[9] T. J. Poskitt, "The consolidation of saturated clay with variable permeability and compressibility," Géotechnique, vol. 19, no. 2, pp. 234-252, 1969.

[10] R. E. Gibson, R. L. Schiffman, and K. W. Cargill, "The theory of one-dimensional consolidation of saturated clays. II. Finite nonlinear consolidation of thick homogeneous layers," $\mathrm{Ca}$ nadian Geotechnical Journal, vol. 18, no. 2, pp. 280-293, 1981.

[11] E. H. Davis and G. P. Raymond, "A non-linear theory of consolidation," Géotechnique, vol. 15, no. 2, pp. 161-173, 1965.

[12] X. Geng and H.-S. Yu, "A large-strain radial consolidation theory for soft clays improved by vertical drains," Géotechnique, vol. 67, no. 11, pp. 1020-1028, 2017.

[13] Z. Hui, On the Theory of Large-Strain Ond Non-linear Rheological Consolidation of Soft Clayey Soils, Zhejiang University, Zhejiang, China, 2004.

[14] Z.-S. Hong, L.-L. Zeng, Y.-J. Cui, Y.-Q. Cai, and C. Lin, "Compression behaviour of natural and reconstituted clays," Géotechnique, vol. 62, no. 4, pp. 291-301, 2012.

[15] X. Geng, B. Indraratna, and C. Rujikiatkamjorn, "Analytical solutions for a single vertical drain with vacuum and timedependent surcharge preloading in membrane and membraneless systems," International Journal of Geomechanics, vol. 10, no. 1, Article ID 012117, 2012.

[16] K. Xie and H. Zhen, "Analysis of one dimensional nonlinear consolidation of layered soils under time-dependent loading," Journal of Zhejiang University, vol. 37, no. 4, p. 426, 2003.

[17] Z. Xie xinyu, "Study on analytical method for one-dimensional nonlinear large deformation consolidation of semiinfinite foundation," Journal of Hydraulic Engineering, vol. 2002, no. 7, pp. 16-22, 2002.

[18] J. Wang, Z. Gao, H. Fu et al., "Effect of surcharge loading rate and mobilized load ratio on the performance of vacuumsurcharge preloading with PVDs," Geotextiles and Geomembranes, vol. 47, no. 2, pp. 121-127, 2019.

[19] S. Liu, X. Geng, H. Sun, Y. Cai, X. Pan, and L. Shi, "Nonlinear consolidation of vertical drains with coupled radial-vertical flow considering time and depth dependent vacuum pressure," International Journal for Numerical and Analytical Methods in Geomechanics, vol. 43, no. 4, pp. 767-780, 2018.

[20] D. W. Taylor, "Fundamentals of soil mechanics," Soil Science, vol. 66 , no. 2 , p. $161,1948$.

[21] J. Wang, "Mandel-cryer effects and influence factors of saturated clay consolidation," Journal of East China Jiaotong University, vol. 30, no. 5, pp. 52-56, 2013.
[22] P. Li, K. Wang, and D. Lu, “Analytical solution of plane-strain poroelasticity due to surface loading within a finite rectangular domain," International Journal of Geomechanics, vol. 17, no. 4, Article ID 04016089, 2016. 